\title{
MAHAR PERNIKAHAN SUKU BUGIS DITINJAU DARI HUKUM ISLAM DI DESA LAPRI KECAMATAN SEBATIK KALIMANTAN UTARA.
}

\author{
Wahyudin.*
}

\begin{abstract}
This work discusses the marriage dowry of the Bugis tribe in terms of Islamic law in Lapri Village, Sebatik District, North Kalimantan. The problems to be examined in this research are, how is the position of the dowry, the process of determining the dowry of the Bugis tribe in Lapri Village, Sebatik District, North Kalimantan and how the Islamic law review regarding the marriage dowry of the Bugis tribe in Lapri Village, Sebatik District, North Kalimantan. The research method used in this research is a type of qualitative research, namely the type of research used to examine the conditions of natural objects. The results showed that the process of determining the dowry or wedding ceremony of the Bugis tribe in Lapri Village, Sebatik District was discussed at the time of ma'duta and the level or amount was decided when mappetu was present, namely, at the meeting of the two parties, both from the bride and the groom-male.
\end{abstract}

Keywords: The Marriage, Bugis, Sebatik 


\section{A. Pendahuluan}

Pernikahan memiliki tujuan untuk membangun keluarga harmonis, sejahtera dan bahagia. Harmonis dimaknai kebersamaan dalam menggunakan hak dan kewajiban keluarga. Sejahtera dimaknai terciptanya ketenangan lahir dan batin disebabkan terpenuhinya keperluan hidup, sehingga timbullah kebahagiaan berupa rasa kasih sayang antara anggota keluarga. Hal ini sejalan dengan firman Allah Swt terdapat dalam al-Qur'an surah Ar-Rūm ayat 21 sebagai berikut;

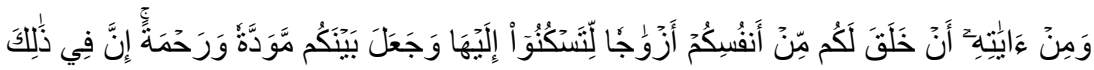

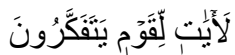

Terjemahan: Dan di antara tanda-tanda kekuasaan-Nya ialah Dia menciptakan untukmu isteri-isteri dari jenismu sendiri, agar kamu cenderung dan merasa tenteram kepadanya, dan dijadikan-Nya diantaramu rasa kasih dan sayang. Sesungguhnya pada yang demikian itu benar-benar terdapat tanda-tanda (kebesaran Allah) bagi kaum yang berfikir. (Q.S Ar-Rum: 21) ${ }^{1}$

Dalam kehidupan zaman modern ini dapat kita lihat pengaruh adat istiadat terhadap sanksinya yang berlaku di sebuah suku di negara Indonesia khususnya Provinsi Sulawesi Tengah. Sulawesi Tengah terdapat beberapa suku baik itu suku Bugis, Jawa akan tetapi suku asli di Sulawesi Tengah adalah suku Kaili. Suku bukan hanya satu suku saja, namun suku kaili terdapat beberapa macam seperti kaili rai, kaili doiriyah, kaili pu, kaili unde, dan masih banyak lagi suku kaili yang lainnya.

Mahar adalah sesuatu yang diberikan oleh pihak suami kepada istri untuk dimiliki sebagai penghalal hubungan mereka. Mahar merupakan bentuk penghargaan yang diberikan seorang suami sebagai bentuk kesetiaan dan cintanya terhadap istri.

Suku Bugis adalah suku perantau, salah satu Daerah yang dipijak adalah Kalimantan Utara Kecamatan Sebatik. Sebagian besar

${ }^{1}$ Departemen Agama RI, Al-Qur'an dan Terjemahanya, (Semarang;PT. Karya Toha Putra, 2002), h 572 
penduduk disana merupakan Suku Bugis perantau dari Sulawesi Selatan yang menetap disana. dimana dalam adat istiadatnya mahar juga termasuk salah satu syarat pernikahan yang harus dipenuhi oleh pihak laki-laki. ${ }^{2}$ Mahar dalam suku Bugis atau lebih dikenal dengan sompa dapat berupa uang atau harta, tetapi yang lebih lazim atau sering didapati dalam pernikahan suku Bugis yaitu berupa barang atau harta, seperti tanah, sawah, hiasan, kebun dan rumah. ${ }^{3}$

Dilain sisi, dalam adat istiadat suku Bugis, sebelum pernikahan terdapat pula beberapa syarat yang harus dipenuhi oleh pihak mempelai pria salah satunya adalah paenre atau uang panai. Uang panai adalah sejumlah uang yang ditetapkan oleh pihak mempelai wanita kepada calon mempelai pria untuk mengetahui kerelaan dan kemampuan calon mempelai pria. Uang panai ini digunakan untuk membiayai pesta pernikahan yang digelar pihak mempelai wanita. ${ }^{4}$

Kebiasaan inilah yang berlaku pada masyarakat Suku Bugis di Desa Lapri Kecamatan Sebatik Kalimantan Utara, padahal pada hakikatnya dalam hukum pernikahan Islam tidak ada kewajiban memberikan uang panai. Kewajiban yang ada dalam pernikahan Islam hanyalah kewajiban memberikan mahar kepada calon istri.

Jenis penelitian yang digunakan dalam penelitian ini adalah jenis penelitian kualitatif. Jenis penelitian kualitatif adalah jenis penelitian yang digunakan untuk meneliti pada kondisi obyek yang alamiah (sebagai lawannya adalah eksperimen). ${ }^{5}$

2 Nurwahidah, Kedudukan Sompa (Mahar) dan Uang Belanja dalam Perkawinan Masyarakat di Kelurahan Pasir Putih Kecematan Sinjai Borong Kabupaten Sinjai, (Skiripsi Sarjana; Universitas Negeri Makassar, 2014), h. 70 (http://eprints.unm.ac.id. / diunduh 31 Juli 2018)

${ }^{3}$ Ibid, h. 71

${ }^{4}$ Lihat, Andi Asyraf, Mahar dan Paenre dalam Adat Bugis, (Skripsi Sarjana; Fakultas Syariah dan Hukum, Univeritas Islam Negeri Syarif Hidayatullah Jakarta, 2015), h. 7 (http://repository.uinjkt.ac.id. / diunduh 31 Juli 2018)

${ }^{5}$ Sugiyono, Memahami Penelitian Kualitatif, (Bandung; Alfabeta, 2009), h. 
Ringkasnya, sebagai permasalahan yang ingin di fokuskan dalam penelitian ini adalah untuk mengetahui tinjauan hukum Islam mengenai mahar pernikahan Suku Bugis yang ada di Desa Lapri Kecamatan Sebatik Kalimantan Utara. Adapun tujuan dalam penelitian adalah pengetahuan, dan pemahaman yang berkenaan dengan pertanyaan dalam rumusan masalah tersebut.

\section{A. Proses Penetapan Mahar Suku Bugis di Desa Lapri Kecamatan Sebatik.}

Pernikahan suku Bugis dianggap sebagai suatu hal yang paling sakral, religius dan sangat dihormati. Dikalangan masyarakat Bugis terdapat pandangan bahwa seseorang dikatakan makalepu (utuh) jika ia telah melangsungkan pernikahan. Pernikahan juga dianggap menyebabkan suatu keluarga terikat oleh suatu ikatan yang disebut Maseddi siri' berarti bersatu dalam mendukung dan mempertahankan kehormatan keluarga. ${ }^{6}$ Adapun tata cara atau proses menuju ke jenjang pernikahan di Suku Bugis dan masyarakat Bugis di Desa Lapri Kecamatan Sebatik adalah sebagai berikut;

\section{a. Mattiro/paita}

Mattiro/paita adalah laki-laki mencari informasi mengenai selak beluk perempuan tersebut mulai dari agamanya, keturunannya, dan akhlaknya. Informasi tersebut diambil dari orang lain, orang yang dekat dengannya ataupun tetangganya. ${ }^{7} \mathrm{Hal}$ ini sudah tidak terlalu di Implementasikan oleh masyrakat suku Bugis di Desa Lapri Kecamatan Sebatik karena dengan adanya perkembangan zaman dan canggihnya teknologi, biasanya calon mempelai laki-laki terjun langsung untuk mencari calon yang akan dinikahinya ataupun calon mempelai laki-laki sudah mempunyai hubungan dengan calon

6 Ahmad Haris Alphaniar, SkripsI; Mahar Perkawinan Adat Bugis Ditinjau dari Perspektif Fiqh Mazhab, (Malang; Universitas Islam Negeri (UIN), 2008), h. 52

${ }^{7}$ Hamidin, Buku Pintar Adat Perkawinan Nusantra, (Jogjakarta; DIVA Press, 2012), h. 125 
mempelai perempuan yakni, pacaran sehingga apabila calon mempelai laki-laki ingin melanjutkan ke pernikahan maka langsung datang melamar ataupun ma $^{\prime} d u t a .{ }^{8}$

b. Mappessek-pessek, ma'manu-manu' atau ma'baja laleng Mappessek-pessek, ma'manu-manu' atau ma'baja laleng adalah suatu cara untuk mengetahui sudah terikat atau tidaknya perempuan yang akan dinikahinya dan untuk mengetahui diterima atau tidak pinangan dari pihak laki-laki. Jika ternyata si perempuan belum ada yang mengikat maka pihak keluarga laki-laki selanjutnya akan memberikan kabar kepada pihak keluarga perempuan bahwa mereka akan datang untuk menyampaikan pinangan. Hal ini juga jarang di praktekkan oleh masyarakat Suku Bugis Desa Lapri Kecamatan Sebatik, karena seperti yang dikemukakan diatas, calon mempelai laki-laki pasti memberikan kabar kepada calon mempelai perempuan bahwa ia datang untuk melamar.

\section{c. Ma'duta}

Setelah kunjungan resmi pertama mengajukan pertanyaan secara tidak langsung, resmi, dan halus, apabila pihak keluarga menyambut baik niat kunjungan pertama dari pihak laki-laki, maka kedua pihak menentukan hari untuk mengajukan lamaran atau ma'duta secara resmi. ${ }^{9}$ Selama proses pelamaran berlangsung, garis keturunan, kekerabatan, status, dan segala sesuatu kedua calon mempelai diteliti lebih jauh sambil membicarakan mahar atau sompa, uang belanja atau uang panai, dan persembahan kepada calon mempelai perempuan dan keluarganya. Setelah semua persyaratan ini disepakati ditentukan hari pertemuan guna mengukuhkan atau mappasirekkeng kesepakatan tersebut. ${ }^{10}$

\section{d. Mapettu ada} 2019

${ }^{8}$ Asrah (Tokoh Adat), Wawancara, Desa Lapri Kecamatan Sebatik, 29 Mei

${ }^{9}$ Rosdalina, Perkawinan Masyarakat Bugis, (Yogyakarta; Istana Publishing, 2016), h. 63

${ }^{10}$ Anas (Ketua RT 03), Wawancara, Desa Lapri Kecamatan Sebatik, 09 Juli 
Mappetu ada adalah memutuskan dan meresmikan segala hasil pembicaraan yang telah diambil pada waktu pelamaran, dalam bahasa Bugis dinamakan mappasirekkeng seperti uang belanja, mahar atau sompa, dan hari akad nikah. Mappetu ada' dilaksanakan dalam bentuk dialog antara pihak laki-laki dan pihak perempuan. Adapun yang dibicarakan dalam mapettu ada' adalah sebagai berikut; ${ }^{11}$

\section{Uang panai atau dui menre}

Uang panai atau dui menre adalah uang belanja yang digunakan untuk membiayai pesta pernikahan yang digelar oleh pihak mempelai perempuan. Uang belanja atau uang panai' ditetapkan berdasarkan kelaziman atau kesepakatan lebih dahulu yang dibicarakan oleh kedua belah pihak laki-laki dan pihak perempuan

\section{Mahar atau sompa}

Mahar atau sompa adalah pemberian pihak laki-laki kepada pihak perempuan berupa uang atau benda akan tetapi lebih lazimnya pada zaman dahulu adalah berupa uang, emas, sawah, kebun. Begitu juga dengan masyarakat Bugis di Desa Lapri Kecamatan Sebatik pada zaman dahulu menggunakan uang, emas, sawah, dan kebun. Akan tetapi dengan adanya perkembangan zaman hal itu sudah tidak dipraktekkan atau diimplementasikan mahar atau sompa pada zaman sekarang lebih condong menggunakan uang dan emas.

\section{Leko atau seserahan}

Leko atau seserahan adalah hadiah-hadiah yang diberikah oleh pihak calon mempelai laki-laki kepada perempuan. Leko atau seserahan ini diberikan waktu mengantar pengantin laki-laki untuk melaksanakan akad nikah, biasanya Leko atau seserahan ini berisikan segala kebutuhan perempuan dari ujung rambut sampai ujung kaki seperti make-up, sandal, sepatu dan lain-lain.

4. Tanra' esso atau penentuan hari

\footnotetext{
${ }^{11}$ Jufri (Tokoh Adat), Wawancara, Desa Lapri Kecamatan Sebatik, 07 Juli
} 
Penentuan acara puncak sangat perlu mempertimbangkan hari-hari yang baik dan waktu luang bagi pihak mepelai laki-laki dan pihak mempelai perempuan.

\section{B. Kedudukan Mahar Pernikahan Suku Bugis di Desa Lapri Kecamatan Sebatik.}

Mahar atau sompa merupakan sesuatu yang sangat sakral dalam pernikahan suku Bugis di Desa Lapri Kecamatan Sebatik dan mahar juga merupakan salah satu satu syarat sahnya pernikahan dan wajib hukumnya memberikan mahar dalam pernikahan masyarakat suku Bugis Desa Lapri di Kecamatan Sebatik. ${ }^{12}$

Masyarakat setempat menganggap bahwa apabila mahar atau sompa telah diberikan maka tidak bisa dikembalikan. ${ }^{13}$ Hal ini diperkuat oleh salah satu tokoh adat yang mengatakan bahwa mahar atau sompa itu kuat posisinya jika si calon mempelai laki-laki telah bersaksi dan menerima calon istrinya sebagai istri yang sah didepan wali nikahnya ataupun penghulu. ${ }^{14}$ mahar atau sompa itu tidak dapat diganggu gugat dan sepenuhnya menjadi hak milik istrinya, jika sang istri sudah meningggal dan mahar atau sompa belum digunakan istri, baik itu dalam untuk kepentingan pribadi ataupun keluarga, maka mahar atau sompa tersebut menjadi milik ahli warisnya ataupun anaknya. ${ }^{15}$ Jika istri meninggal tapi tidak mempunyai anak maka mahar atau sompa tersebut menjadi milik orangtuanya. ${ }^{16}$

Pada zaman dahulu praktek pemberian mahar atau sompa suku Bugis di Desa Lapri Kecamatan Sebatik, hanya berupa uang,

\section{Mei 2019}

${ }^{12}$ Zulkifli (Tokoh Adat), Wawancara, Desa Lapri Kecamatan Sebatik 17 Juni 2019

${ }^{13}$ H. Arifin, (Tokoh Adat), Wawancara, Desa Lapri Kecamatan Sebatik, 03 Mei 2019

${ }^{14}$ Hj. Hartati (Tokoh Adat), Wawancara, Desa Lapri Kecamatan Sebatik18 Juni 2019

${ }^{15}$ H. Arifin, (Tokoh Adat), Wawancara ,Desa Lapri Kecamatan Sebatik, 03 Juli 2019

${ }^{16}$ Hasmida (Masyarakat), Wawancara, Desa Lapri Kecamatan Sebatik, 03 
sawah, kebun,tanah dan emas akan tetapi hal ini mulai terkikis ataupun tidak dipraktekkan. Pada saat ini mayoritas masyarakat setempat lebih senang memberikan mahar atau sompa hanya dalam berbentuk uang dan emas dan jumlah nominalnya tergolong tidak terlalu memberatkan. ${ }^{17}$ Serta dalam menentukan kadar jumlah mahar atau sompa itu tidaklah menjadi sebuah permasalahan besar, karena bagi masyarakat setempat dalam menentukan kadar jumlah mahar atau sompa hanya berdasarkan dari keikhlasan dan kemampuan dari pihak laki-laki serta kesepakatan kedua belah pihak. ${ }^{18}$

Berikut ini penulis mencoba memaparkan uang belanja atau uang panai pada zaman dahulu dan pada zaman sekarang di Desa Lapri Kecamatan Sebatik;

1. Mahar atau sompa dan uang belanja atau uang panai pada zaman dahulu di Desa Lapri Kecamatan Sebatik;

\begin{tabular}{|c|c|c|c|}
\hline NO & NAMA PASANGAN & MAHAR & UANG PANAI \\
\hline 1. & Sakka/Hartati & $\begin{array}{l}\text { Emas } 3 \text { gram dan uang } \mathrm{Rm} \text {. } \\
3.000\end{array}$ & Rm. 1000 \\
\hline 2. & Ambo Asse/Hali & Sebidang tanah perumahan & Rm. 700 \\
\hline 3. & Dg. Mallongi/Asrah & $\begin{array}{c}\text { Emas } 2 \text { gram dan sebidang } \\
\text { tanah }\end{array}$ & Rm. 1000 \\
\hline 4. & $\begin{array}{l}\text { H. Nurung/Hj. } \\
\text { Dasmawati }\end{array}$ & Uang Rm. 5.000 & Rm. 1000 \\
\hline 5. & Hasanuddin/Hasmida & Sepetak sawah & Rm. 800 \\
\hline 6. & Tahang/Samsidar & Emas 2 gram & Rm. 500 \\
\hline
\end{tabular}

Mei 2019

${ }^{17}$ Syarifuddin (Penghulu), Wawancara, Desa Lapri Kecamatan Sebatik, 24

18 Samsul Rizal, ( Tokoh Agama), Wawancara, Desa Lapri Kecamatan Sebatik, 09 Juli 2019 


\begin{tabular}{|c|c|c|c|}
\hline 7. & Zulkifli/Hayati & Uang Rm. 5.000 & Rm. 500 \\
\hline 8. & Acottang/Hasmida & Uang Rm. 5000 & Rm. 500 \\
\hline
\end{tabular}

Sumber: Masyarakat Desa Lapri Kecamatan Sebatik Utara

2. Mahar atau sompa dan uang belanja atau uang panai pada zaman sekarang di Desa Lapri Kecamatan Sebatik;

\begin{tabular}{|c|c|c|c|c|}
\hline NO & $\begin{array}{l}\text { NAMA } \\
\text { PASANGAN }\end{array}$ & MAHAR & UANG PANAI & TAHUN \\
\hline 1. & Ical/syamsiah & Emas 2 gram & Rp. 15. 000.000,. & 2011 \\
\hline & Jali1/Imar & $\begin{array}{c}\text { Emas 2 gram dan uang } \\
\text { Rp. 100.000 }\end{array}$ & $\begin{array}{c}\text { Emas 3 gram dan } \\
\text { uang Rp.20. } \\
\text { 000.000 }\end{array}$ & 2013 \\
\hline & Saharuddin/Wana & uangR. 300.000,. & Rp. 15. 000.000,. & 2014 \\
\hline & Anwar/Jumriah & Uang Rp.500.000 & Rp. 15. 000.000,. & 2015 \\
\hline & Kalam/Mimi & $\begin{array}{c}\text { Emas 2 gram dan uang } \\
\text { Rp. 100,000 }\end{array}$ & Rp. 15. 000.000,. & 2016 \\
\hline & Diway/ita & $\begin{array}{c}\text { Separangkat alat solat } \\
\text { dan uang } \\
\text { Rp. 100.000 }\end{array}$ & Rp. 17. 500.000,. & 2017 \\
\hline & Jurafid/Arni & $\begin{array}{c}\text { Emas 2 gram dan uang } \\
\text { Rp. 100,000 }\end{array}$ & Rp. 35.000.000,. & 2019 \\
\hline
\end{tabular}

Sumber: Masyarakat Desa Lapri Kecamatan Sebatik Utara

Jika dilihat dari jumlah mahar atau sompa pada zaman dahulu hingga pada zaman sekarang jelas terdapat perbedaan seperti yang telah diuraikan diatas, pada zaman dahulu mahar atau sompa lebih besar kadar atau jumlah berbeda dengan zaman sekarang dimana kadar atau jumlah mahar atau sompa lebih rendah. 
Begitu juga dengan uang belanja atau uang panai pada zaman dahalu lebih rendah daripada zaman sekarang yang kadar, jumlah atau nominalnya cukup besar. Masyarakat setempat beralasan bahwa uang belanja atau uang panai nominalnya cukup tinggi pada zaman sekarang karena harga barang-barang pada zaman sekarang itu cukup mahal oleh karena itu untuk membeli barang-barang guna keperluan pesta pernikahan maka uang belanja atau uang panai perlu dinaikkan. ${ }^{19}$

\section{Tinjauan Hukum Islam Mengenai Mahar atau Sompa Masyarakat suku Bugis di Desa Lapri Kecamatan Sebatik.}

Mahar atau sompa menurut masyarakat suku Bugis di Desa Lapri Kecamatan Sebatik adalah sesuatu yang wajib diberikan calon mempelai laki-laki kepada calon mempelai perempuan sebagai bentuk penghargaan kepada calon mempelai perempuan dan jumlah atau kadarnya ditentukan dengan keikhlasan dan kerelaan calon mempelai laki-laki serta kesapakatan kedua belah pihak. Hal ini sesuai dengan firman Allah Swt;

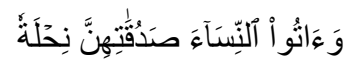

Terjemhan; Berikanlah maskawin (mahar) kepada wanita (yang kamu nikahi) sebagai pemberian dengan penuh kerelaan. (QS. AnNisa: 4). ${ }^{20}$

Dengan demikian, mahar atau sompa dalam pernikahan suku Bugis di Desa Lapri sejalan dengan hukum Islam yang sama-sama mewajibkan memberikan mahar kepada calon mempelai perempuan. Perbedaan hanyalah kadar atau jumlahnya, karena pada zaman dahulu mahar atau sompa kadar atau jumlahnya lebih besar daripada zaman sekarang. Hukum Islam juga tidak menetapkan batas minimal dan maksimal dalam menetapkan mahar. Rasulullah Saw juga Mei 2019

${ }^{19}$ Pa'ege (Tokoh Adat), Wawancara, Desa Lapri Kecamatan Sebatik, 29

${ }^{20}$ Departemen Agama, Al-Qur'an dan Terjemahanya, (Semarang;PT. Karya Toha Putra, 2002), h. 100 
menganjurkan agar tidak berlebih-lebihan dalam memberikan mahar, Rasulullah Saw bersabda;

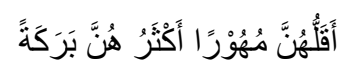

Artinya; "Wanita yang sedikit maharnya lebih banyak berkahnya "21

Dan dalam Hadist lain;

Artinya; "Sebaik-baik mahar adalah yang paling murah" 22

$$
\text { خَيْرُ الصَّدَا قِ أَيْسَرُ هُنَّ }
$$

Menurut masyarakat suku Bugis Desa Lapri Kecamatan Sebatik, mahar atau sompa yang akan diberikan kepada calon mempelai perempuan yang akan dinikahinya yaitu harta atau benda yang berharga, harta atau benda yang jelas keadaannya atau wujudnya, harta atau benda yang halal. Hal ini juga sejalan dengan hukum Islam. Perbedaan hanyalah Ulama membolehkan memberikan mahar atau sompa dalam bentuk jasa akan tetapi, sebagian masyarakat setempat tidak memperkenankan hal itu, dengan alasan memberikan mahar atau sompa Sebaiknya dalam bentuk harta atau benda dan yang jelas keadaan dan bentuknya.

Menurut penulis hal itu tidak menyeleweng ataupun kontra dalam hukum Islam karena memberikan mahar dalam hukum Islam itu wajib, akan tetapi tidak mewajibkan memberikan mahar dalam bentuk jasa. Memberikan mahar dalam bentuk jasa hanyalah sebuah pilihan dari beberapa pilihan yang ada serta mahar atau sompa juga diberikan secara sukarela oleh setiap calon mempelai laki-laki masyarakat Desa Lapri kepada calon mempelai perempuan.

Meskipun demikian, hal itu tidaklah sepenuhnya bertentangan dengan hukum Islam meskipun tidak ada ditemukan dalil atau ijma Ulama yang mewajibkan mempelai laki-laki untuk memberikan uang belanja atau uang panai', seperti yang diketahui bahwa dalam agama Islam dalam konsep muamalah dan adat istiadat semua itu tergantung

${ }^{21}$ Nail Al-Nauthar, jus 6, h. 312.

${ }^{22}$ Abdul Aziz Muhammad Azzam dan Abdul Wahab Sayyed Hawwas, loc.cit 
kepada manusia untuk mengatur bagaiamana baiknya dengan catatan tidak bertentangan dengan aqidah dan hukum Islam.

Selain itu, Imam Ahmad dan selainnya dari para fuqaha ahli hadist juga mengatakan (Yusuf al-Qordhawi), sesungguhnya yang asal pada perkara ibadat itu ialah tauqif, yakni dilihat dahulu dan tidak dijadikan sebagai hukum Syariat kecuali apa yang disyariatkan Allah Swt, kalau tidak termasuklah kita dalam firman Allah Swt;

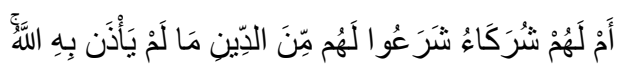

Terjemahan; Apakah mereka itu mempunyai kongsi yang membuat hukum agama untuk diri mereka, sesuatu yang tidak sama sekali diizinkan Allah Swt.(Q.S As-Syura;21) ${ }^{23}$

Sedang dalam persoalan adat kebiasaan maka asal hukumnya dimaafkan dan tidak dilarang daripadanya kecuali apa yang sudah diharamkan oleh Allah Swt. Allah Swt berfirman;

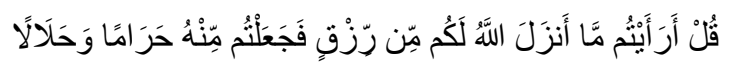

Terjemahan; Katakanlah: "Terangkanlah kepadaku tentang rezeki yang diturunkan Allah kepadamu, lalu kamu jadikan sebagiannya haram dan (sebagiannya) halal. (Q.S Yunus; 59). ${ }^{24}$

Jika dilihat dari sisi bahayanya ataupun mudharatnya, maka menurut realita yang penulis amati, sampai saat ini belum ada peristiwa ataupun kejadian yang penulis dapati di masyarakat suku Bugis Desa Lapri Kecamatan Sebatik, yang setelah menikah mendapatkan pertengkaran mengenai uang belanja atau uang panai', apalagi hidupnya sengsara setelah menikah akibat terlalu besar uang belanja atau uang panai yang dipatok oleh pihak mempelai perempuan serta tidak ada juga para pemuda ataupun keluarga

\footnotetext{
${ }^{23}$ Departemen Agama, op. Cit, h. 696

${ }^{24} \mathrm{Ibid}$, h. 288
} 
mempelai laki-laki yang berhutang agar dapat memenuhi uang belanja ataupun, uang panai' yang dipatok oleh pihak mempelai perempuan.

\section{B. Penutup}

Dari hasil peneltian dan pembahasan yang dipaparkan, maka dapat ditarik kesimpulan sebagai berikut;

1. Mahar adalah sesuatu pemberian yang wajib diberikan calon mempelai laki-laki kepada calon mempelai perempuan dengan sukarela, keikhlasan serta kesepakatan dari kedua belahpihak .

2. Proses penetapan mahar suku Bugis di Desa Lapri Kecamatan Sebatik dibicarakan pada saat ma'duta dan diputuskan kadar atau jumlahnya pada saat mappetu ada' dilaksanakan yaitu pada saat pertemuan pihak mempelai laki-laki dan pihak mempelai perempuan.

3. Tinjauan hukum Islam mengenai mahar atau sompa suku Bugis di Desa Lapri Kecamatan Sebatik tidaklah bertentangan dengan hukum Islam dikarenakan dalam memberikan mahar walaupun pada zaman dahulu suku Bugis di Sulawesi Selatan dalam menentukan kadar atau jumlah mahar bergantung kepada strata sosial atau tingkatan sosial seseorang, akan tetapi hal itu berbeda dengan pandangan masayarakat suku Bugis di Desa Lapri Kecamatan Sebatik Kalimantan Utara, masyarakat setempat sudah tidak mengimplementasikan menentukan mahar berdasarkan tingkatan sosial akan tetapi, masyarakat setempat menggunakan asas kesederhanaan, keikhlasan, kerelaan serta kesepakatan dari kedua belah pihak.

\section{Referensi}

Abdullah, Sulaiman, Sumber Hukum Islam, Jakarta; Sinar Grafika, 1995

Ahmad, Alphaniar, Haris, SkripsI; Mahar Perkawinan Adat Bugis Ditinjau dari Perspektif Fiqh Mazhab, Malang; Universitas Islam Negeri (UIN), 2008 
Comparativa Vol. 1 No. 2, Juli - Desember 2020

Ahmad, Kadir, Abdul, Sistem Perkwainan Sulawesi Selatan dan Sulawesi Barat, Makassar; Indobis, 2006

Ali, Zainuddin, Antropologi Hukum, (Palu: Yayasan Indonesia Baru, 2013

Azzam, Muhammad, Aziz, Abdul dan Sayyed Hawwas Abdul Wahab Sayyed, Fiqh Munakahat, Cet. III, Jakarta: Imprint Bumi Aksara, 2014

Asy-Syarqawi, Hasiyyah, 'Ala Syarh At-Tahrir, Jus 2, h. 251 dan Mughni Al-Muhtaj, Jus 3,

Bungi, Burhan, H.M, Metode Kualitatif, Jakarta; Kencana, 2010

Departemen, Agama, RI, Al-Qur'an dan Terjemahanya, Semarang;PT. Karya Toha Putra, 2002

Djazuli, A, Ilmu Fiqh: Penggalian, Perkembangan dan Penerapan Hukum Islam, Jakarta; Kencana Prenada Media Group, 2005

Hadi, kusuma Hilman, Pengantar Ilmu Hukum Adat di Indonesia, Bandung; Mandar Maju, 2002

Hamidin, Buku Pintar Adat Perkawinan Nusantra, Jogjakarta; DIVA Press, 2012

Khalil, Rasyad, Hasan, Tarikh Tasyri', Jakarta; Amzah, 2009

Khallaf, Abdul, Wahhab, Kaidah-Kaidah Hukum Islam (Ilmu Ushulul Fiqhi), Jakarta;PT. Raja Grafindo Persada, 1996

Kelsen, Hans, Dasar-Dasar Hukum Normatif, Terj. Nurulita Yusron, Cet. II; Bandung: Nusa Media, 2009

Lamalonggeng, Riadi, Asmat, Dinamika Perkawinan Adat dalam Masyarakat Bugis Bone, Makassar; Dinas Kebudayaan dan Pariwisata Kabupaten Bone, 2007 
Madani, Kumpulan Peraturan Tentang Hukum Islam di Indonesia, Ed. 2; Jakarta; Kencana, 2013

Mukhtar, Kamal, asas-asas Hukum Islam tentang perkawinan, Jakarta; Bulan Bintang, 1974

Mahalli, Mudjab, Ahmad, Wahai Pemuda Menikahlah, jogjakarta;Menera Kudus, 2002

Margono, S., Metodologi Penelitian Pendidikan, Cet III, Jakarta; Rineka Cipta, 2000

Milles, B. Matthew, et Al-Qualitative data analisys, diterjemahkan oleh Tjetjep Rohendi rohidi dengan judul analisis data kualitatif, buku sumber tentang metode-metode baru, Cet I, Jakarta; UI Pres, 1992

Nurjannah, Mahar Pernikahan, Jogjakarta: Prismasophie Press, 2003

Nurwahidah, Kedudukan Sompa (Mahar) dan Uang Belanja dalam Perkawinan Masyarakat di Kelurahan Pasir Putih Kecematan Sinjai Borong Kabupaten Sinjai, (Skiripsi Sarjana; Universitas Negeri Makassar, 2014), (http://eprints.unm.ac.id. / diunduh 31 Juli 2018)

Nurjannah, Mahar Pernikahan, Jogjakarta: Prismasophie Press, 2003

Pa'ege (Tokoh Adat), Wawancara, Desa Lapri Kecamatan Sebatik, 29 Mei 2019

Pelras, Christian, Manusia Bugis, Jakarta; EFEO, 2005

Rahman, Abd, (Kepala Desa), Wawancara Pribadi, Desa Lapri Kecamatan Sebatik, 28 Mei 2019

Rosdalina, Perkawinan Masyarakat Bugis, Yogyakarta; Istana Publishing, 2016

Rusyd Ibnu, al-Mujtahid wa nihayah al-Muqtashid, Mesir; Darl alfikr, t.t

Samsul, Rizal, (Mantan Kepala Desa Lapri), Wawancara Pribadi, Desa Lapri Kecamatan Sebatik, 09 Juli 2019 
Comparativa Vol. 1 No. 2, Juli - Desember 2020

Sakka, (Tokoh Adat), Wawancara, Desa Lapri Kecamatan Sebatik, 28 Mei 2019

Samsidar, (Masyarakat), Wawancara, Desa Lapri Kecamatan Sebatik, 25 Mei 2019

Sofyan, Yayan, Islam Negara: Transformasi Hukum Perkawinan Islam dalam Hukum Nasional, Jakarta: PT. Wahana Semesta Intermedia, 2012

Sudiyat, Imam, Hukum Adat Sketsa Asas, Yogyakarta: Liberty, 2007

Soekanto, Soerjono, Hukum Adat Indonesia, (Jakarta: Raja Grafindo Persada, 2003

Sugiyono, Metode Penelitian Kualitatif, Kuantitatif, dan $R \& B$, Bandung; Alfabeta, 2010

Syarifuddin, Amir, Hukum Perkawinan Islam di Indonesia, Cet. 5; Jakarta; Kencana, 2014

Syukur, Sarmin, Sumber-Sumber Hukum Islam, Surabaya; Al-Ikhlas 2010

Tihami H.M.A, dan Sahrani Sohari, Fiqh Munakahat, Cet. II, Jakarta: PT. Raja Grafindo Persada, 2010

Umar, Anas, Panduan Iman dan Pegawai Syara', Palu; Majlis Dzikir dan Ta'lim Syubbaanul Khairaat, 2016

Umar, Nasaruddin, Kodrat Perempuan dalam Islam, Jakarta; Lembaga Kajian Agama dan Gender, 1999

Winarmo, Surakhmand, Dasar dan Teknik Research, Pengantar Metodologi Ilmiah, Ed VI, Cet III, Bandung; Tarsito 1985

Zulkifli (Tokoh Adat), Wawancara Pribadi, Desa Lapri Kecamatan Sebatik, 17 Mei 2019 
Zaydan, Karim, Abdul, Al-Mufassal fi Ahkam al-Mar'ah wa al-Bait al-Muslim fi as-Syari'ah allslamiyyah, Beirut: Muassasah alRisalah, 1993

Zahro, Abu, Ushul Fiqh, Surabaya; Pustaka Firdaus, 2011

* Alumni prodi ahwal syakhsiyyah Universitas Alkhairaat Palu, Mahasiswa prodi magister Hukum Keluarga Islam Pascasarjana IAIN Palu 